\begin{tabular}{|c|c|}
\hline PORT SAID ENGINEERING RESEARCH JOURNAL \\
Faculty of Engineering - Port Said University \\
Volume (21) No. (2) September 2017 pp. 111:119
\end{tabular}

\title{
AXIAL TENSILE CAPACITY OF HELICAL PILES FROM FIELD TESTS AND NUMERICAL STUDY
}

\author{
Tarek N. Saleml/Mohamed M. Hussein ${ }^{2}$
}

\begin{abstract}
Helical piles are used to support structures subjected to axial and lateral loads. The main object of the paper is to study the behavior of helical piles in cohesive and cohesionless soils using a full scale field testing. Then, the field test results are numerically verified using the finite element analysis software ADINA [1]. The tested piles are having two circular pitched bearing plates welded at a spacing of two and half the helix diameter welded to a solid-circular shaft. Field and numerical results showed that the most effective parameters on the helical pile uplift capacity are the embedment depth, soil strength, and number of helix, along with other parameters.
\end{abstract}

Key words: Helical Piles, Numerical Analysis, Software ADINA, Embedment Ratio, Number of Helix.

\section{INTRODUCTION}

Helical piles (also referred to anchors, anchor piles, or screw piles) have most commonly used as "anchors", to resist tensile loads in supporting structures such as lighthouse beacons, buried pipelines, utility poles, guyed towers, and transmission towers. In recent decades, their applications in engineering projects have expanded to both support and rehabilitate structures under tensile, compressive, and lateral loading, El-Naggar and Livneh, (2008) [9].

The combination of variable shaft lengths and helix diameters has expanded the range of projects for which helical piles may be suitable. The installation method of helical piles allows them to reach a great depth with the addition of extension segments in the field, and thus increases their versatility. Helical piles are installed almost vibration free, through the use of simple mechanical torque, which reduces damage to adjacent structures, and they can be constructed without excavating soil or even pouring concrete. This allows cleaner and quicker installation and makes them both environmentally friendly and cost effective, El-Naggar and Livneh, (2008) [9].

Early approaches towards the evaluation of helical anchor capacity involved examining the behavior of shallow single plate anchors. Utilizing either assumed or observed failure surfaces within the soil adjacent to the pile, several studies characterize the failure geometry for anchors. Majer (1955) [15], Mors (1959) [19], and Ireland (1963) [13] proposed highly idealized conical failure shape, reaching the surface at an angle of $\left(45^{\circ}\right.$ $+\phi / 2$ ) to the vertical, in which $\phi$ is the internal friction angle of the soil.

${ }^{I}$ Professor, Faculty of Engineering, Zagazig University, Egypt,

Email: nageeb2@yahoo.com

${ }^{2}$ Demonstrator, Faculty of Engineering, Zagazig University, Egypt, Email:eng_magdy2020@yahoo.com
Mooney et al. (1985) [18] proposed idealized failure surfaces for shallow and deep anchor conditions for helical piles in clay and silt based on laboratory model tests. A procedure similar to the work conducted by Meyerhof and Adams (1968) [16], Adams and Hayes (1967) [2], Adams and Klym (1971) [3], and Mitsch and Clemence (1985) [17], is adopted in Mooney's model, as shown in Figures (1) and (2).

Laboratory investigations of anchor behavior and failure geometry include half-scale and full-scale laboratory models by Balla (1961) [5], Sutherland (1965) [26], Downs and Chieurzzi (1966) [8], Meyerhof and Adams (1968) [16], Clemence and Vee-Saert (1977) [7], Sutherland et al. (1982) [27], Murray and Geddes (1987) [20], Weizhi and Fragaszy (1988) [28], Hoyt and Clemence (1989) [12], Ghaly and Hanna (1991) [11], Ghaly et al. (1991) [10], and Narasimha Rao et al. (1993) [23]. Their results included estimations of a failure surface reaching the ground surface at angles between $\phi / 4$ and $\phi / 2$ to the vertical. The behaviors of shallow and deep anchors are classified through either a failure surface extending to the ground surface (shallow anchor behavior), or a localized shearing failure (deep anchor behavior).

Based on laboratory results, Balla (1961) [5] established a breakout factor as a dimensionless quantity related to the peak pullout load plotted with respect of the embedment ratio (H/D): where "H" is the depth of embedment of the upper helix and "D" is the diameter of the largest helix), which can also be used to classify shallow and deep anchors. Narasimha Rao et al. (1989) [21] conducted an experimental program with multihelix anchors showing that pile ultimate uplift capacity in cohesive soils increases with (i) the number of helical plates; (ii) decreasing soil moisture content; and (iii) increasing soil consistency index. 
The development of a cylindrical failure surface below the top helix is shown for piles with small helical spacing (i.e., $S / D_{a v} \leq 3$, where $S$ is the spacing between helical plates and $D_{a v}$ is the average helical diameter). In this regard, the results of Narasimha Rao and Prasad (1991) [22] and Narasimha Rao et al. (1993) [23] are consistent with the findings of Mitsch and Clemence (1985) [17], who presented results of both laboratory and field investigations on triple helix anchors. Mitsch and Clemence (1985) [17] provided a method for estimating the uplift capacity of shallow and deep helical piles, depending on pile embedment, helical spacing, and soil conditions.

Aside from the empirical estimation of helical pile capacity through a correlation to installation torque, there presently exists two general theories describing the failure mechanism of multi-helix anchors, namely through cylindrical shearing, involving the development of a failure surface between the inter-helical soil, and through individual bearing of each helical plate, where each helix behaves independently. The distinction between these methods has significant implications on pile ultimate capacity and is of particular interest for this investigation, Livneh and El-Naggar, (2008) [9]

Ultimate Pullout Capacity

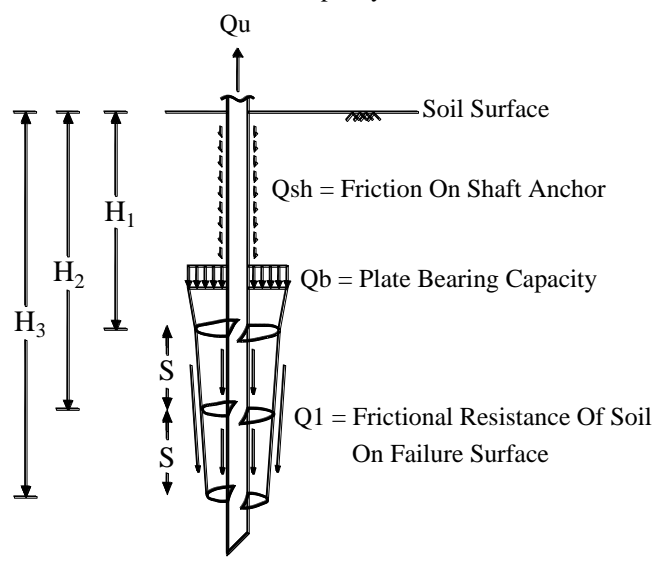

Figure (1): Proposed Failure Mode for Multi Helix Anchors in Clay and Silt, (after Mooney et al., 1985).

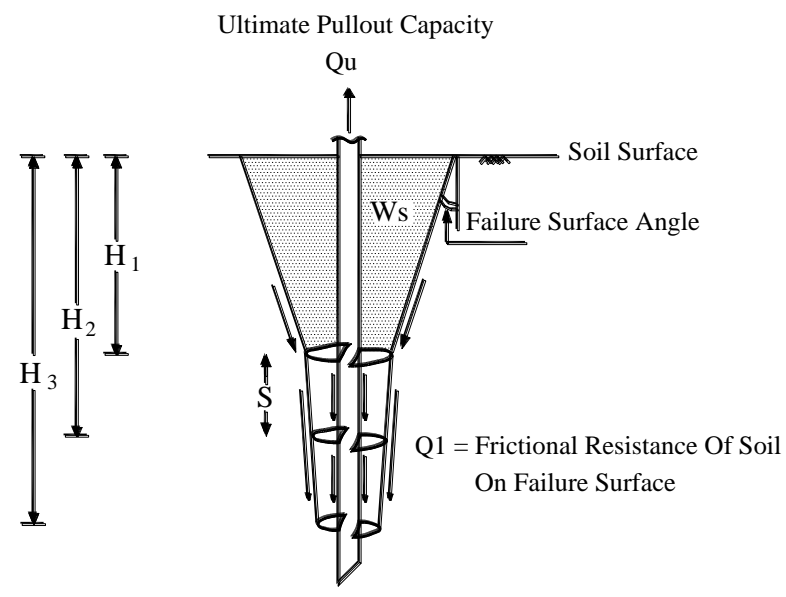

Figure (2): Failure Surface for Multi Helix Anchors in Sand, (after Mitsch and Clemence, 1985).

\section{2- COMPARISON BETWEEN HELICAL PILE AND ORDINARY PILE}

It should be noted that the helical piles are different from normal piles in many aspects. The differences includes the methods of calculating both the skin friction and end bearing values, the behavior under compression and tension loads, the installation method and the behavior in different soil types. Thus, helical piles could not be compared with normal piles.

\section{3- EXPERIMENTAL INVESTIGATION}

The main objective of the experimental work is to evaluate the axial tensile behavior and capacity of helical piles in different consistencies and types in the field.

\section{3-1- Pile Description}

The test helical pile consists of two helical steel bearing plates of $200.0 \mathrm{~mm}$ diameter each, welded to a central steel solid shaft of $45.0 \mathrm{~mm}$ diameter. The helical shape of the bearing plates allows for minimum soil disturbance during installation and because each helix is a single $76 \mathrm{~mm}$ pitch of a screw thread, the system can literally screw into the ground without obstruction.

The path of each consecutive helix follows the same path as the preceding one during installation in such scenario. The lead section of the pile, shown in Figure (3), supports the loads applied to the system by transferring them to the surrounding soils. The spacing between the plates is approximately two times and half the helix diameter, i.e., $\mathrm{S} / \mathrm{D}=2.50$, in which $\mathrm{S}$ is the helix spacing and $\mathrm{D}$ is the helix diameter. The total helical pile length is $2.0 \mathrm{~m}$, and the pile length inside the soil is $1.90 \mathrm{~m}$.

\section{3-2 Pile Installation}

All the surface loose materials are removed, and then the helical pile is placed vertically in place. A wooden beam is placed horizontally at a special groove at the pile head. Two men began rotating the wooden rod and the helical pile screw soil until it reached its final position to be ready for testing.

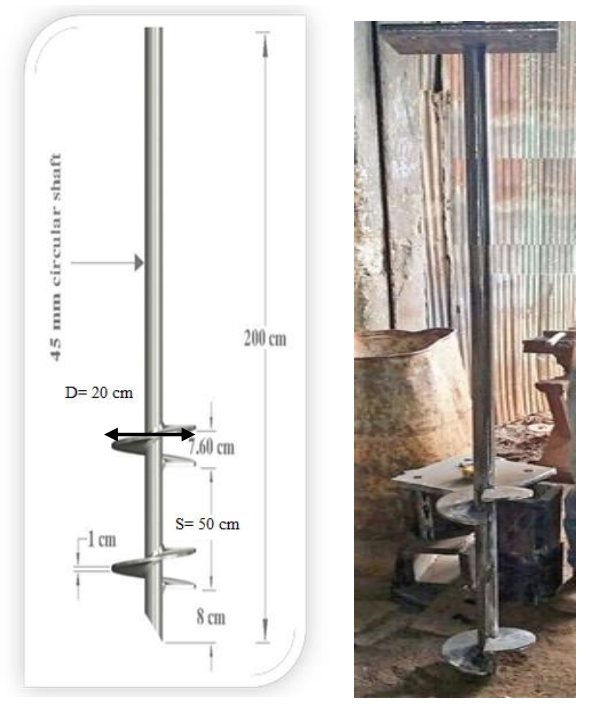

Figure (3): Test Helical Pile Geometry, Dimensions and Shape. 


\section{3-3- Loading System}

For the test program, adequate capacity is delivered by a hydraulic jack of 16 ton capacity. The load applied by the jack is controlled by supplying fluid pressure through a manual hydraulic pump. The measurement of the axial tensile load applied to the test pile is based on the pressure gauge reading on the hydraulic pump as a backup.

Wooden cribbing is installed at about five times pile diameter from the tested piles according to ASTM D3689-07[4] to allow for free movement of the pile during loading. Figure (4) illustrates the general layout of tension pile load testing setup. The figure shows the reaction frame, which consists of cribbing, the load beam (steel 270 I-beam), and leveled surface for the loading jack. The setup for tension load testing is shown in Figure (5).

Load is transferred to the pile by using $35 \mathrm{~mm}$ diameter high strength steel bars connected to steel plate placed on top of hydraulic jack and bolted to the test pile, the reaction is provided by timber cribbing.

\section{3-4- Displacement Measurement}

The vertical pile movements during the tension test are measured using displacement dial gauges. The gauges are calibrated prior to testing, placed on each side of the test pile diametrically and attached to the test pile using magnetic setting. Average displacement readings from the dial gauges are plotted against the applied jack loads to yield load-displacement curves for each tested pile. These curves are used to establish the ultimate pile capacity for the different tested cases.

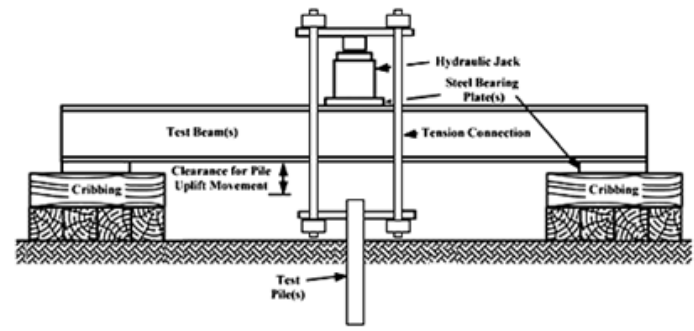

Figure (4): Typical Helical Pile Tension Test Setup Using Hydraulic Jack.

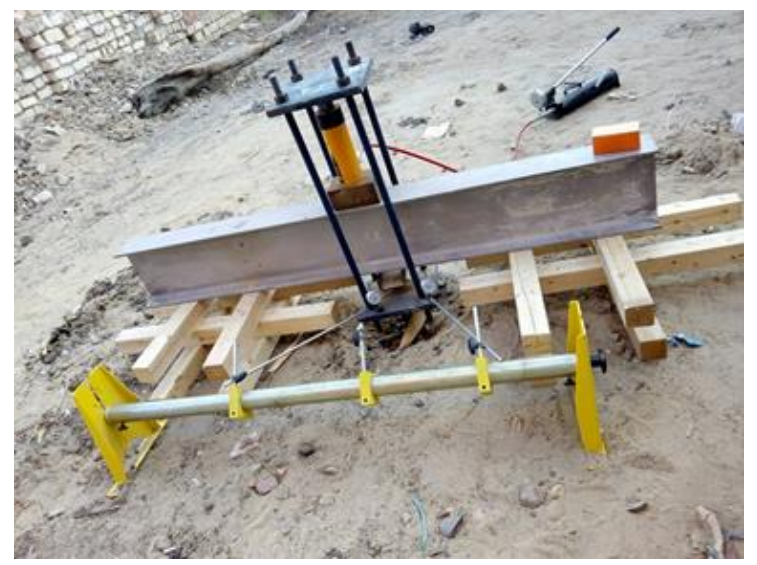

Figure (5): Field Helical Pile Test Setup.

\section{3-5- Tested Soil Types and Properties}

The load testing program is conducted at four different locations in Sharkia Governorate, Egypt. The soils are mainly cohesive in the three sites and cohesionless in the fourth. These soils are; medium stiff silty clay (site 1), stiff silty clay (site 2), very stiff silty clay (site 3 ), and dense sand in (site 4). The soil shear strength parameters for the different sites are presented in Table (1), as obtained from the soil investigation reports of each site. It should be noted that there is no large differences between the undrained cohesion of the soils tested in sites (2) and (3), and consequently, the difference between the behaviors in the two cases is not large.

Table 1: Soil Properties for Different Sites.

\begin{tabular}{c|c|c|l}
\hline \hline Location & $\begin{array}{c}\text { Unconfined } \\
\text { Compressive } \\
\text { Strength } \\
\left(\mathrm{q}_{\mathrm{u}}\right) \mathrm{kPa}\end{array}$ & $\begin{array}{c}\text { Angle of } \\
\text { Internal } \\
\text { Friction } \\
\left(\phi^{\circ}\right)\end{array}$ & Description \\
\hline Site (1) & 80 & 0 & $\begin{array}{l}\text { Medium stiff } \\
\text { silty clay }\end{array}$ \\
\hline Site (2) & 190 & 0 & $\begin{array}{l}\text { Stiff silty } \\
\text { clay }\end{array}$ \\
\hline Site (3) & 210 & 0 & $\begin{array}{l}\text { Very stiff } \\
\text { silty clay }\end{array}$ \\
\hline Site (4) & 0.00 & 39 & Dense Sand \\
\hline \hline
\end{tabular}

\section{3-6- Pile Testing Criteria}

The axial pile load tests are conducted according to ASTM D-3689-07[4] in quick load test method in which the loads are applied in increments of $5 \mathrm{~min}$. time intervals. Each pile is loaded to failure in increments of 10 to $15 \%$ of the proposed test load.

Constant time intervals of minimum of 5 minutes are used to permit adequate time for recording the displacement readings. The tests are carried out up to the ultimate load that is defined as the load corresponding to a pile top upward movement greater than $10 \%$ of the helix diameter according to BS-8004 criterion (BSI 1986)[6], and as presented in ISSMFE (1985)[14].

\section{4- NUMERICAL MODEL}

Field test results obtained during helical pile testing is used to verify the numerical model performed using the finite element software ADINA, (2017). The finite element model main objective is modeling helical pile load-transfer behavior for the different field tests. Upon model calibration and verification with the experimental data, the numerical model is extended to model different helical pile geometries and soil types, along with other factors.

A finite element mesh sensitivity study is performed to eliminate the effect of the model boundaries on the soil behavior, and the used total number of elements is equal to 1302 element. The helical pile is modeled using an 
axi-symmetric model, the lateral side boundaries are modeled using horizontal rollers allowing for soil vertical movement, while hinges are used to model the soil domain lower boundaries restricting the soil movement at this side, as shown in Figure (6).

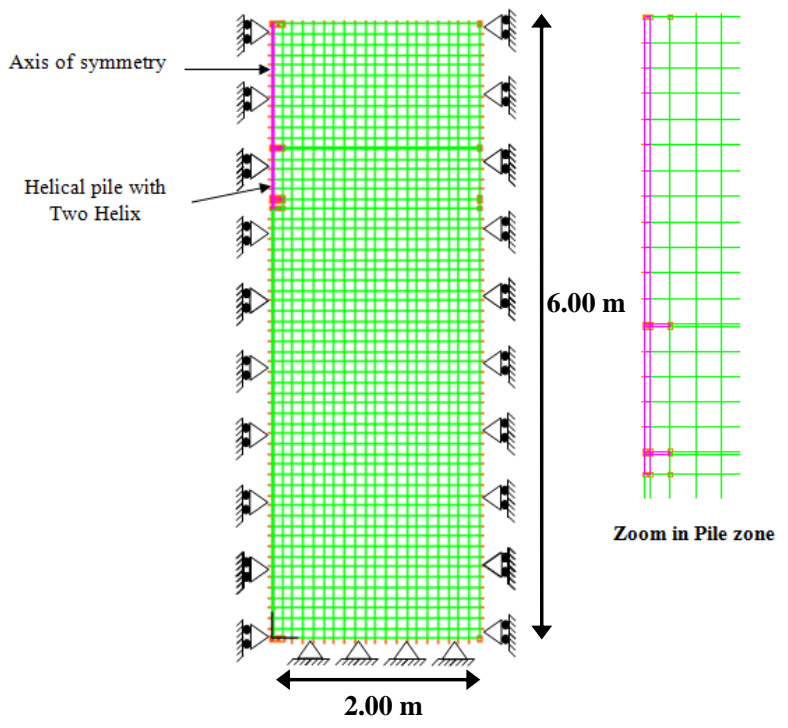

Figure (6): Helical Pile Numerical Model.

\section{4-1- Soil Material Model}

The cam-clay model is used to model the soil behavior of cohesive soils of which the model parameters are obtained from consolidation tests. On the other hand, Mohr-Coulomb model is used for modeling the behavior of cohesionless soils and ground water table at depth $2.00 \mathrm{~m}$ from ground surface.

The helical pile itself is made of steel and modeled as a linear elastic material. Summary of the input parameters of all the used models and their parameters are presented in Tables (2) and (3).

Table (2) Mohr-Coulomb and Pile Model Parameters.

\begin{tabular}{l|c|c}
\hline \multicolumn{1}{c|}{ Parameter } & $\begin{array}{c}\text { Sandy Soil } \\
\text { Mohr Columb } \\
\text { Model }\end{array}$ & $\begin{array}{c}\text { Helical Pile } \\
\text { Elastic (Isotropic } \\
\text { Model) }\end{array}$ \\
\hline \hline $\begin{array}{l}\text { Modulus of } \\
\text { Elasticity, E } \\
\left(\mathrm{MN} / \mathrm{m}^{2}\right)\end{array}$ & 140.0 & $2 * 10^{5}$ \\
\hline $\begin{array}{l}\text { Unit Weight, } \gamma \\
\left(\mathrm{kN} / \mathrm{m}^{3}\right)\end{array}$ & 18.0 & 78.50 \\
\hline Poisson's ratio, $v$ & 0.32 & 0.30 \\
\hline $\begin{array}{l}\text { Angle of Friction } \\
\left({ }^{\circ}\right)\end{array}$ & $\phi=39^{\circ}$ & \\
\hline \hline
\end{tabular}

Table (3) Cam-Clay Soil Model Parameters.

\begin{tabular}{r|c|c|c|c|c|c}
\hline \hline No & Soil Type & $\boldsymbol{M}$ & $\lambda$ & $\kappa$ & $\begin{array}{c}\mathrm{E} \\
(\mathrm{MPa})\end{array}$ & $\begin{array}{c}\gamma \\
\left(\mathrm{kN} / \mathrm{m}^{3}\right)\end{array}$ \\
\hline \hline 1. & $\begin{array}{c}\text { Medium } \\
\text { Stiff Silty } \\
\text { Clay }\end{array}$ & 1.00 & 0.12 & 0.024 & 4.50 & 17.0 \\
\hline \hline
\end{tabular}

\begin{tabular}{r|c|c|c|c|c|c}
\hline \hline No & Soil Type & $\boldsymbol{M}$ & $\lambda$ & $\kappa$ & $\begin{array}{c}\mathrm{E} \\
(\mathrm{MPa})\end{array}$ & $\begin{array}{c}\gamma \\
\left(\mathrm{kN} / \mathrm{m}^{3}\right)\end{array}$ \\
\hline \hline 2. & $\begin{array}{c}\text { Stiff Silty } \\
\text { Clay }\end{array}$ & 2.00 & 0.090 & 0.020 & 9.50 & 18.0 \\
\hline 3. & $\begin{array}{c}\text { Very Stiff } \\
\text { Silty Clay }\end{array}$ & 2.082 & 0.080 & 0.018 & 10.50 & 18.0 \\
\hline \hline
\end{tabular}

\section{5-EXPERIMENTAL RESULTS AND NUMERICAL VERIFICATION}

The load-deflection curves up to failure for the tested tension loaded helical piles tested in different soils are presented herein. It is noticed that the first loading step resulted in minimal soil displacements due to many factors which affect the pile behavior under such low uplift load.

These small displacements are mainly attributed to the effect of pile weight, soil initial resistance to upward movement under the effect of its downward weight, and developing skin resistance of the helixes and the shaft. This behavior is also noticed by many authors; Papadopoulou et al., (2014) [24], Zhang (1999) [29], and Perko (2009) [25].

Figure (7) shows a consistent increase in the measured displacements when increasing the applied loads till failure. The tested soil is medium stiff silty clay and the failure took place at about $18.30 \mathrm{kN}$, as defined in the failure criteria. Results of the numerical analysis also shows the same trend with slightly higher computed vertical displacements.

The maximum difference between the measured and computed uplift loads at the maximum allowable displacement is about $4.37 \%$. In general, good agreement is noticed between the measured and computed loaddisplacement behavior of the helical piles with maximum difference of about $7.70 \%$ at $20 \mathrm{kN}$ uplift load along the different loading steps. It should be noted that this relatively low ultimate load is mainly due to the relatively softer consistency of the soil in the site.

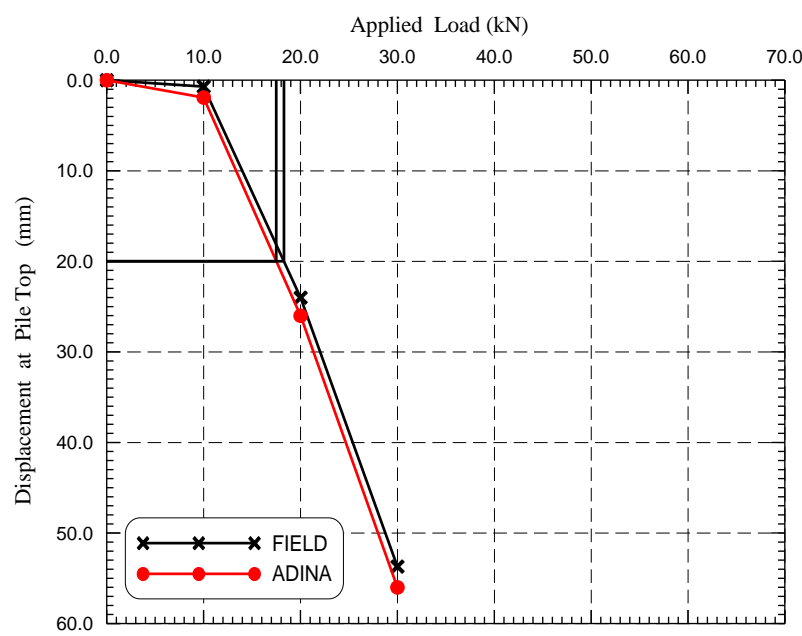

Figure (7): Tensile Load Deflection Curve for a Pile Tested in Medium Stiff Silty Clay. 
Figure (8) shows the relation between the applied uplift loads and the measured vertical displacements for the case of stiff silty clay. Test results showed that failure took place at relatively higher load of $42.10 \mathrm{kN}$ due to testing in stiffer soil than the previous case. The ultimate load is corresponding to an allowable displacement of 0.10 D. Numerical results are also consistent with the experimental ones with a maximum difference of about $4.80 \%$ at failure.

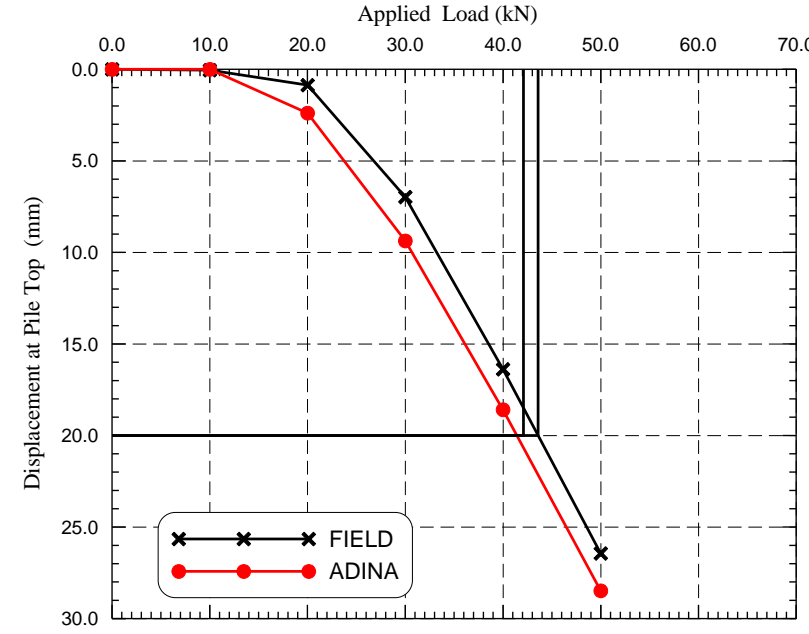

Figure (8): Tensile Load Deflection Curve for a Pile Tested in Stiff Silty Clay.

The relation between the applied uplift load and the measured vertical displacement is presented in Figure (9) for very stiff silty clay. Higher clay consistency in this site causes failure to take place at relatively higher load of about $45.0 \mathrm{kN}$.

The maximum difference between numerical results and experimental ones is about $1.56 \%$ at failure. It should be noted that the relatively large difference between the measured and computed displacements took place at specific load of $30 \mathrm{kN}$, in which numerical results looks more consistent than the experimental ones. This may be due to specific field conditions under this loading step only.

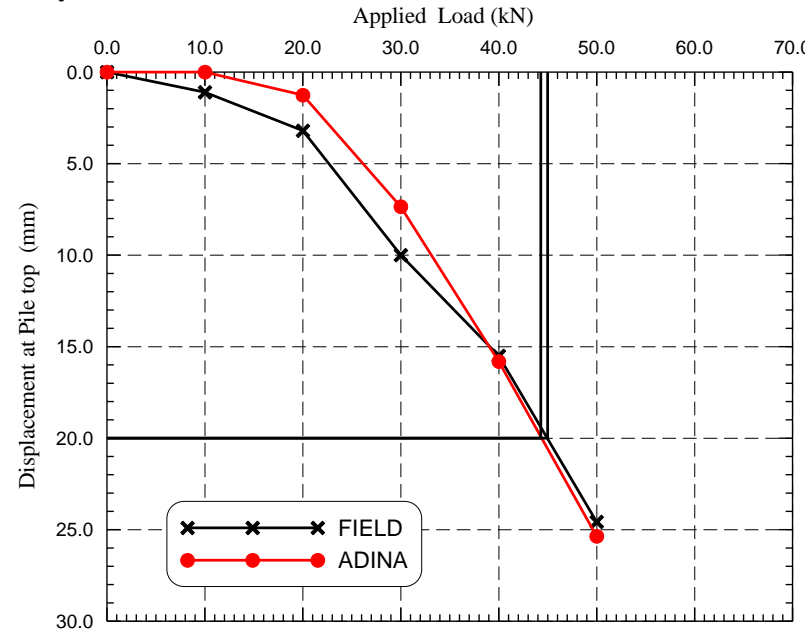

Figure (9): Tensile Load Deflection Curve for a Pile Tested in Very Stiff Silty Clay.
Results of the helical pile case tested in dense sand are shown in Figure (10). The numerical results are also consistent with the experimental ones with differences of about $2.90 \%$ at failure, and a maximum difference along all the loading steps took place at $40 \mathrm{kN}$ and was about $8.90 \%$.

At an allowable displacement of $0.10 \mathrm{D}$, the failure load in this case is equal to $52.30 \mathrm{kN}$, slightly higher than the maximum loads measured in the very stiff silty clay soils. Thus, tension loaded helical piles are more effective in sand than those constructed in clays.

Applied Load (kN)

$\begin{array}{llllllllllllll}0.0 & 5.0 & 10.0 & 15.0 & 20.0 & 25.0 & 30.0 & 35.0 & 40.0 & 45.0 & 50.0 & 55.0 & 60.0 & 65.0\end{array}$

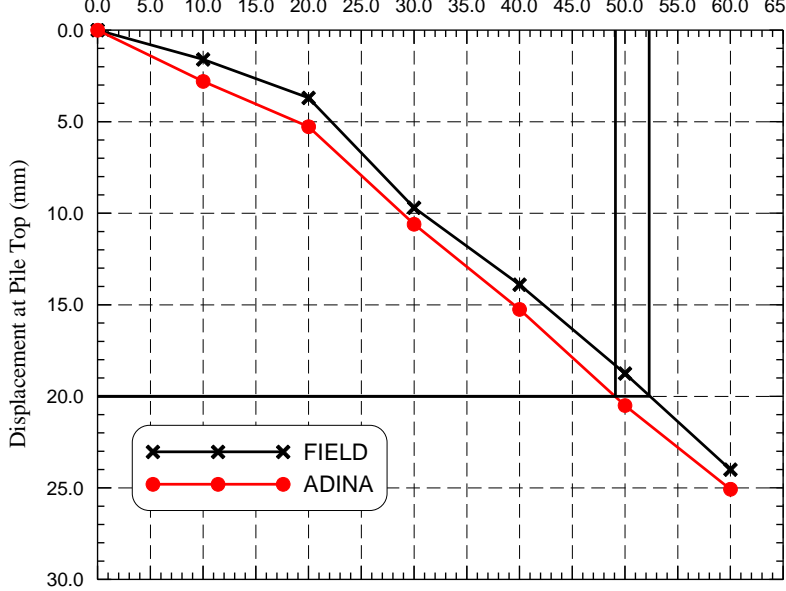

Figure (10): Tensile Load Deflection Curve for a Pile Tested in Dense Sand.

\section{6- NUMERICAL MODEL AND PARAMETRIC STUDY RESULTS}

Analysis of the numerical model results are presented herein in two main forms. First, colored contour shading of the stresses and vertical soil movements within the analyzed soil domain, and graphs showing relations between the different studied parameters.

A numerical parametric study is conducted to better understand and shed more light into the behavior of helical piles considering different practical pile configurations and soil properties. The studied parameters included the pile inter-helix spacing, the helix diameter, the pile embedment depth, and the number of helixes, along with different soil properties.

The numerical model of the helical piles is having the following configurations; circular steel shaft with diameter equal $\mathrm{d}=5 \mathrm{~cm}$ which differs slightly from field test, wing ratio ranges between $2 \mathrm{~d}$ and $5 \mathrm{~d}$ (which is the ratio between the helix diameter $\mathrm{D}$ and the shaft diameter $d)$. The inter-helix spacing ratio, $S_{r}=$ inter-helix spacing/helix diameter ranges between 1 and 5 , with an increment of 1 . The pile embedment depth ranges 
between $3 \mathrm{D}$ and $8 \mathrm{D}$, in which $\mathrm{D}$ is the helix diameter, and number of helixes ranges between 2 and 5 .

\section{7- ANALYSIS OF THE RESULTS}

\section{7-1- Helical Pile Vertical Displacement in Cohesive Soils}

The vertical displacements (heave) that took place due to the helical pile tension loading in different silty clay consistencies are presented in Figures (11-a, 12-a, and 13-a). The maximum vertical displacement took place at the helical pile tip. The figures also show that the zone of maximum displacements took place between the two helixes with slightly larger diameter than the actual helix diameter. Moving above the upper helix, the zone of high displacements is slightly larger than the shaft diameter. Thus, the helical pile pull-out resistance is dependent upon the helix diameter, spacing between helixes, and the shaft diameter. Moreover, typically higher undrained cohesions will result in higher helical pile pull-out resistance.
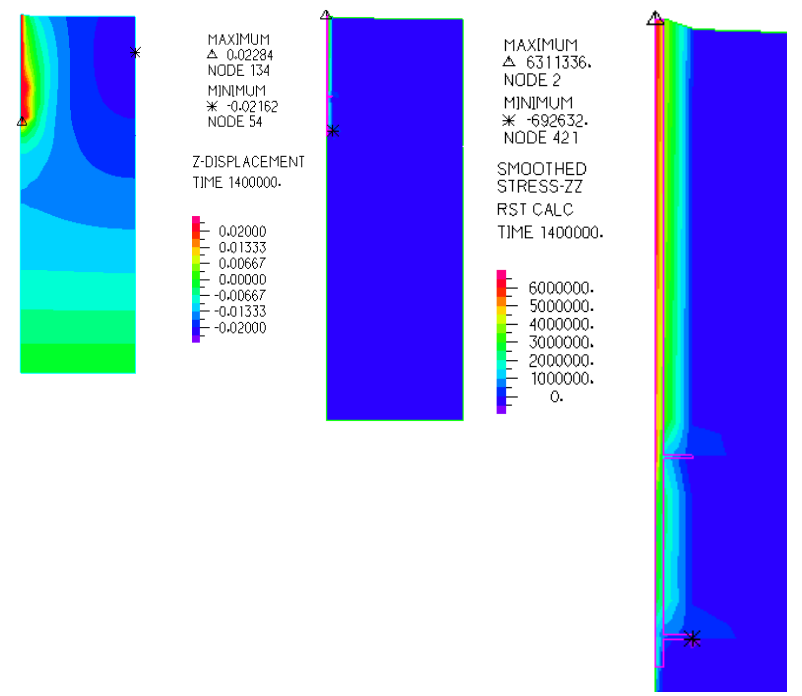

(a) Vertical Displacement Due to Uplift Force. (b) Vertical Stress Due to Uplift Force. (c) Zoom in Pile Vertical Stress Zone.
Figure 11: Numerical Results Output for Medium Stiff Silty Clay Case.

\section{7-2- Helical Pile Vertical Stresses in Cohesive Soils}

Contours of vertical stresses within the helical pile soil domain are presented in Figures (11-b, 12-b, and 13-b). The maximum vertical stresses took place at the pile head, and the minimum took place at the helix plate end. The affected stress zone is approximately equal to or slightly larger than the helix diameter and extends along the whole pile length in cohesive soils. The lower cylindrical stress zone diameter is about 0.70 the helix diameter, followed by a transition zone between the lower and upper cylinders. The average upper cylinder stress zone diameter is about 1.10 the helix diameter.
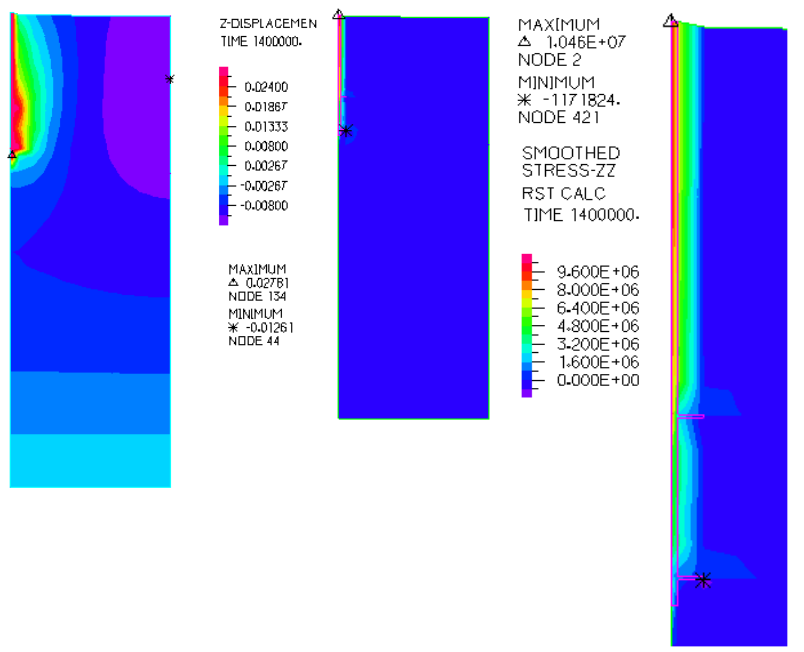

(a) Vertical

Displacement Due

(b) Vertical Stress

(c) Zoom in Due to Uplift Force.

Pile Vertical Stress Zone.

Figure 12:Numerical Results Output for Stiff Silty Clay Case.
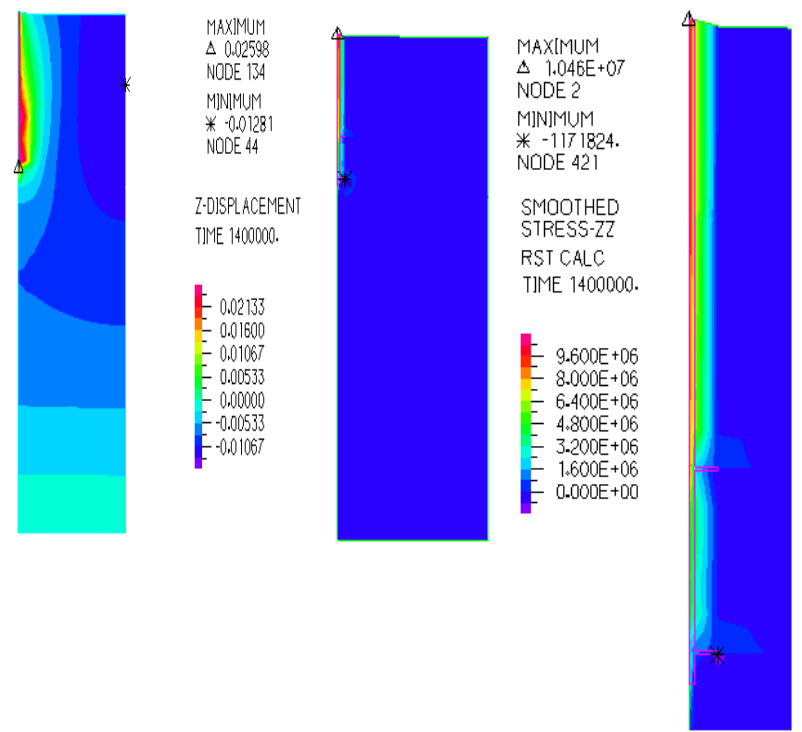

(a) Vertical

Displacement Due

(b) Vertical Stress

(c) Zoom in Due to Uplift Force.

Pile Vertical Stress Zone.

Figure 13: Numerical Results Output for the Very Stiff Silty Clay Case.

\section{7-3- Helical Pile Vertical Displacement in Cohesionless Soils}

Figure (14-a) shows somewhat different behavior in which the maximum vertical displacements took place at the helical pile head. Moreover, the distributions of the highest displacements are mostly along the helical pile shaft, with somewhat lower effect of the helix diameter. 
In addition, the vertical displacements diameter zone tend to increase when coming closer to the soil surface showing what looks like an inverted cone, assuring the results of Mitsch and Clemence, 1985. The zone of highest vertical displacements tends to decrease when moving up from the upper helix up to the ground surface.

\section{7- 4- Helical Pile Vertical Stresses in Cohesionless Soils.}

In sandy soils the stresses are concentrated around the helix positions as shown in Figure (14-b), with an external stress zone diameter of about 0.80 the actual helix diameter and took place between the two helix. The average upper cylinder diameter is about 1.30 the helix diameter and extended to soil surface with an inverted cone also.
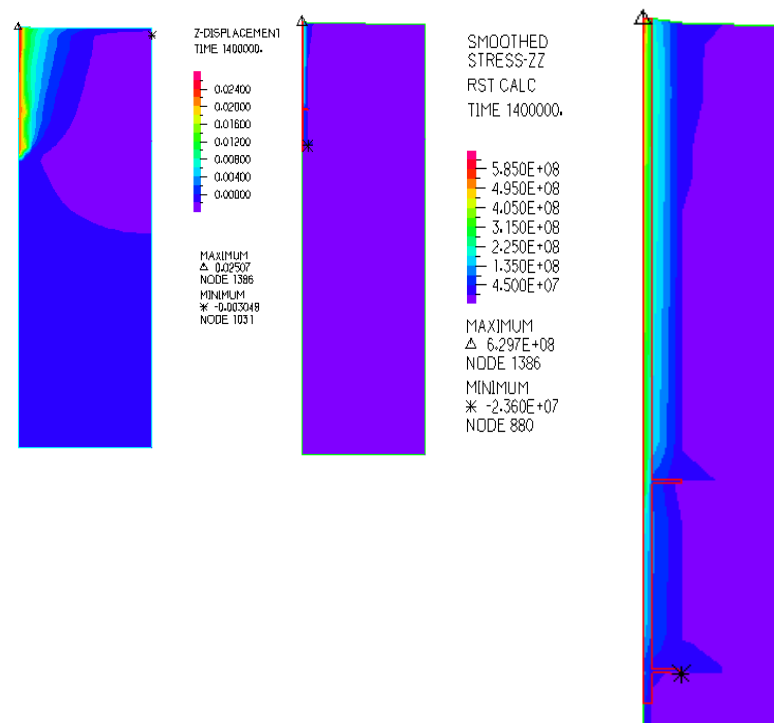
(a) Vertical
Displacement
(b) Vertical Stress Due to Uplift Force.
(c) Zoom in Pile Vertical Due to Uplift Force.

Figure 14: Numerical Results Output for the Dense Sand Case.

\section{7-5- Effect of Wing Ratio on the Calculated Displacements}

Figure (15) shows the relation between the wing ratio and the calculated displacement ratio $\delta_{\mathrm{v}} / \mathrm{D}_{\text {helix }}$, in which $\delta_{\mathrm{v}}$ is the computed vertical displacements, and $D_{\text {helix }}$ is the helix diameter. Results show that increasing the wing ratio resulted in a noticeable decrease in the calculated vertical displacement ratio by about $33 \%$ when increasing the wing ratio from 2 to 4 . Further increase in the wing ratio does not induce noticeable decrease in the displacement ratio which is only about $2 \%$ when increasing the wing ratio from 4 to 5 . Thus, increasing the wing ratio more than 4 is not effective in reducing the helical pile vertical displacements, or in other words in increasing the helical pile capacity.

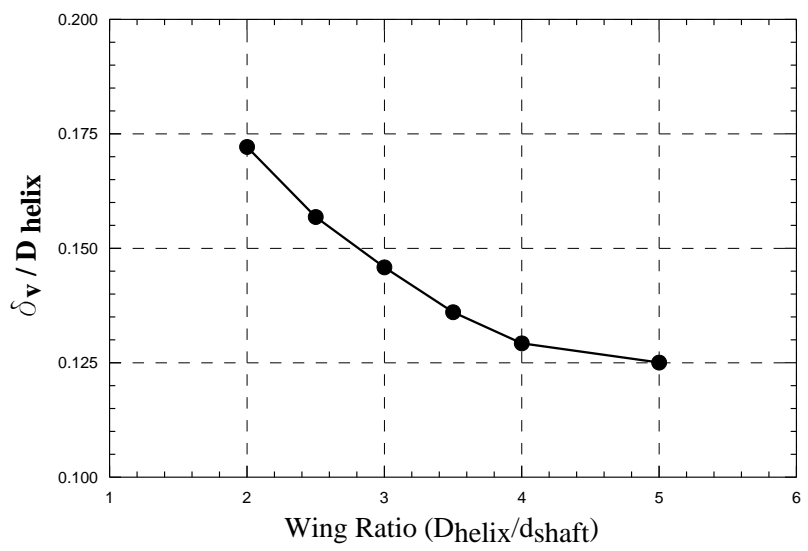

Figure 15: Relationship between the Displacement Ratio $\left(\delta_{v} / D_{\text {helix }}\right)$ and the Wing Ratio $\left(D_{\text {helix }} / \mathrm{d}_{\text {shaft }}\right)$ for Sand.

\section{7-6- Effect of the Helix Spacing}

The relation between helix spacing ratio $\left(S_{r}\right)$ and displacement ratio $\delta_{\mathrm{v}} / \mathrm{D}_{\text {helix }}$ is presented in Figure (16). Results show that increasing the helix spacing ratio resulted in noticeable decrease in computed displacement ratio by nearly $61 \%$ when increasing spacing ratio from 1 to 3 . After that the effect of increasing the helix spacing ratio is less noticeable with nearly $31 \%$ by increasing $\left(\mathrm{S}_{\mathrm{r}}\right)$ from 3 to 4.5 . Therefore, the helical pile capacity slightly increases with increasing the $S / D$ ratios.

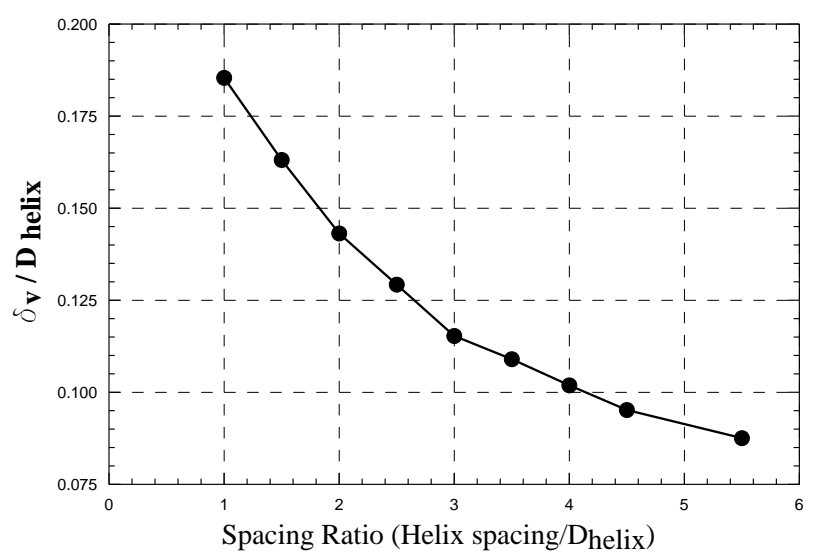

Figure 16: Relationship between the Displacement/ $\mathrm{D}_{\text {helix }}$ and the Helix Spacing Ratio $\left(S_{r}\right)$ for Sand.

\section{7-7- Effect of Embedment Ratio, (H/D)}

The embedment ratio (H/D) and displacement ratio $\delta_{\mathrm{v}}$ $/ \mathrm{D}_{\text {helix }}$ relation is presented in Figure (17). The figure shows consistent decrease in the calculated vertical displacements when increasing the embedment depth, remembering that the helix diameter is essentially constant. Starting from an embedment depth of 3 times the helix diameter up to 7 times the helix diameter resulted in a noticeable decrease in the calculated 
vertical displacements at failure and therefore, a consistent increase in the helical pile tension capacity. This reduction reached about $140 \%$ of the original value. However, increasing embedment ratio from 7 to 10 resulted in only $13 \%$ in the calculated vertical displacements. Experimental evidence presented by Mitsch and clemence, (1985) showed that increasing the embedment ratio up to 7.0 noticeably increased the uplift capacity factor, while higher embedment ratios has small effect on increasing the axial helical pile capacity.

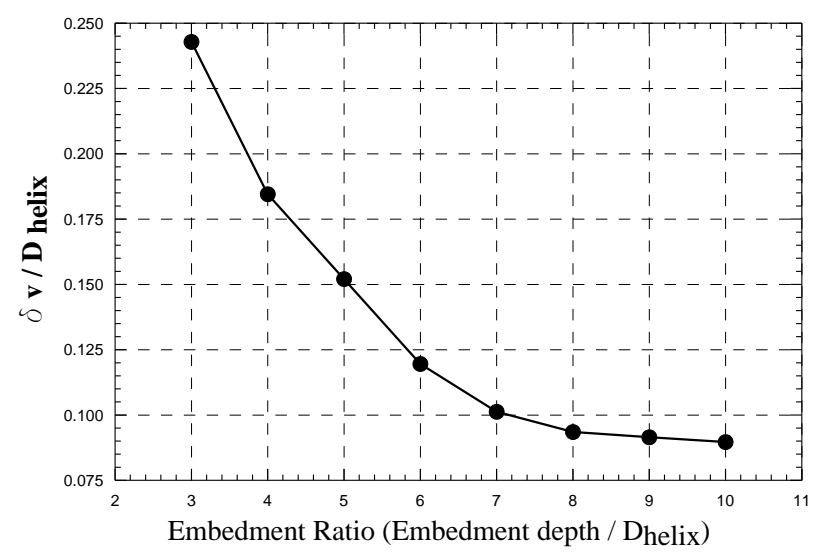

Figure 17: Relationship between the Displacement Ratio and the Embedment Ratio for Sand.

\section{7-8- Effect of Number of Helixes}

The most effective factor in increasing the helical pile tension capacity is increasing the number of helixes in a single helical pile. Increasing the number of helixes from 2 to 5 resulted in a consistent increase in the allowable axial capacity of the helical pile from $65.50 \mathrm{kN}$ up to $122.0 \mathrm{kN}$ or nearly by about $86 \%$. More precisely, the allowable tension capacities for 3 helixes is $90.0 \mathrm{kN}, 4$ helixes is $108.0 \mathrm{kN}$, and 5 helixes of $122.0 \mathrm{kN}$; or in other words with increased capacity ratios of $37 \%, 65 \%$, $86 \%$ respectively. The net increase for each additional helix is $37 \%, 28 \%$, and $21 \%$ respectively. This behavior is attributed to the increased surface frictional area when increasing the number of helixes along the pile shaft.

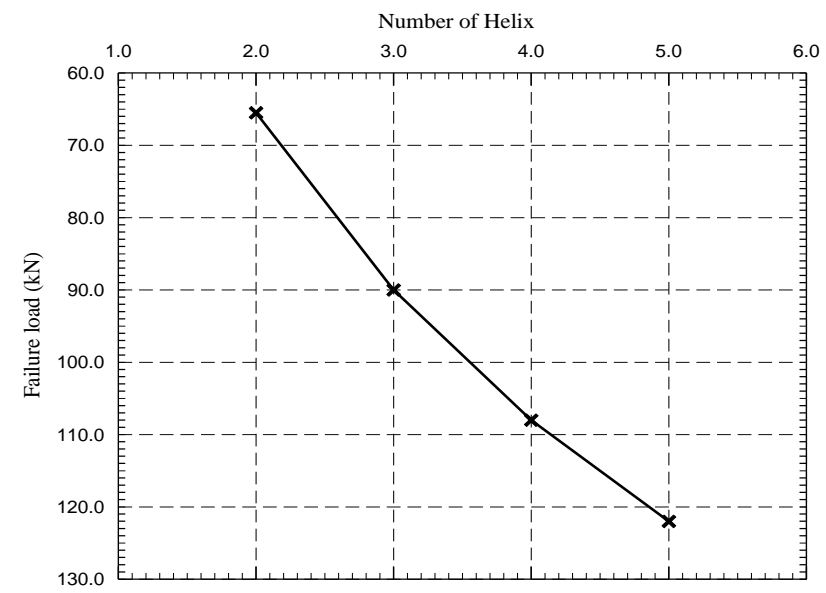

Figure 18: Relationship between the Ultimate Uplift and Number of Helix in Sand Soil.

\section{8- Conclusions}

A comprehensive experimental and numerical investigation is conducted to assess the tensile performance of circular-shaft helical piles. Full-scale field experimental testing program is conducted to assess the load-displacement behavior of tension loaded helical piles. The experimental tests are numerically verified and their results are in good agreement with the full scale load test results. A numerical parametric study is then performed to account for the effect of many factors. Based on the experimental and numerical results, the following conclusions are drawn:

1- The most effective parameters that have the major effect on the helical pile uplift capacity are the embedment ratio and number of helixes. Increasing the embedment ratio up to 7 resulted in an increase in the helical pile capacity by nearly $123 \%$. Moreover, increasing the number of helixes from 2 to 5 resulted in increasing the helical pile tension capacity by nearly $86 \%$.

2- The most efficient helical pile configurations for sandy soil are to choose the helix diameter about 4 times the shaft diameter as concluded from figure (15), helix spacing about 3 times the helix diameter as concluded from figure (16), and the embedment depth of 7 times the helix diameter as concluded from figure (17).

3- In cohesive soils, the highest vertical displacements are concentrated between the pile helixes and along the upper pile shaft. However, in cohesionless soils, the highest vertical displacements are concentrated along the helixes, the shaft, with tendency of forming an upper inverted cone along the helical pile shaft.

4- High zones of vertical stresses are concentrated along the helical pile. The diameter of this zone is approximately equal to or slightly higher than the helix diameter and extend along the whole pile length in cohesive soils. The lower cylindrical stress zone diameter is about 0.70 the helix diameter, followed by a transition zone between the lower and upper cylinders. The average upper stress zone diameter is cylinder having a diameter of about 1.10 the helix diameter.

5- In cohesionless soils, the high vertical stress zones are concentrated along the pile shaft and helix surrounding zones especially between the two helixes. However, moving from the upper helix upward to the ground surface, an inverted vertical stress cone is formed. The external vertical stress zone diameter is about 0.50 the actual helix diameter and took place between the two helixes. The average upper vertical stress zone is cylinder having a diameter of about 0.80 the helix diameter and openly extended from the upper helix into the soil surface. 


\section{REFERENCE}

[1] ADINA, (2017), "Automatic Dynamic Incremental Nonlinear Analysis Software", ADINA R \& D, Inc.

[2] Adams, J.I., and Hayes, D.C., (1967), "The Uplift Capacity of Shallow Foundation", Ontario Hydro Research Quarterly, Vol. 19, pp. 1-13.

[3] Adams, J.I., and Klym, T.W., (1971), "A Study of Anchors for Transmission Tower Foundation", Canadian Geotechnical Journal, Vol. 9, No. 1, pp. 89-104.

[4] ASTM, (2007), "Standard Test Methods for Deep Foundations Under Static Axial Tensile Load", ASTM-D-3689, ASTM International, West Conshohocken, Pa.

[5] Balla, A., (1961), "The Resistance to Breaking out of Mushroom Foundations for Pylons", Proceedings of $5^{\text {th }}$ International Conference on Soil Mechanics and Foundation Engineering, Paris, France, Vol. (1), pp. 569-576.

[6] BSI, (1986), "British Standard Code of Practice for Foundations", BS 8004, British Standards Institution (BSI), London.

[7] Clemence, S.P.N., and Veesaert, C.J., (1977), "Dynamic Pullout Resistance of Anchors in Sand", In Proceedings of the International Symposium On Soil-Structure Interaction, Roorkee, India., pp. 389-397.

[8] Downs, D.I., and Chieurzzi, R., (1966), "Transmission tower foundations", Journal of the Power Division, Vol. (92) (P02): 91-114.

[9] El-Naggar, M.H., and Livneh, B., (2008), "Axial Testing and Numerical Modeling of Square Shaft Helical Piles under Compressive and Tensile Loading", Canadian Geotechnical Journal, Vol. (45), pp.1142-1155.

[10] Ghaly, A.M., Hanna, A.M., and Hanna, M.S., (1991), "Uplift Behavior of Screw Anchors in Sand", ASCE, Journal of Geotechnical Engineering Division, Vol. (117), pp.773-793.

[11] Ghaly, A., and Hanna, A., (1991), "Experimental and Theoretical Studies on Installation Torque of Screw Anchors", Canadian Geotechnical Journal, Vol. (28), pp. 353-364.

[12] Hoyt, R.M., and Clemence, S.P., (1989), "Uplift Capacity of Helical Anchors in Soil", In Proceedings of the $12^{\text {th }}$ International Conference on Soil Mechanics and Foundation Engineering (ISSMFE), Rio de Janeiro, Brazil, Vol. (2), pp.1019-1022.

[13] Ireland, H.O., (1963), "Discussion, Uplift Resistance of Transmission Tower Footings", Journal of the Power Division, Vol. (89), pp. 115-118.

[14] ISSMFE, (1985), "Axial Pile Loading Test-Part I: Static Loading", Geotechnical Testing Journal, ASTM, Vol. (8), No. 2, pp. 79-80.

[15] Majer, J., (1955), "Zurberechnung Von Zugfundamenten Osterreichis Che Bauzeitgs Chrift" Vol. (10), pp. 85-90. [In German.]
[16] Meyerhof, G.G., and Adams, J.I., (1968), "The ultimate Uplift Capacity of Foundations", Canadian Geotechnical Journal, Vol. (5), No. 4, pp. 225-244.

[17] Mitsch, M.P., and Clemence, S.P., (1985), "The Uplift Capacity of Helix Anchors in Sand", Uplift Behavior of Anchor Foundations in Soil, Proceedings of ASCE, New York, N.Y., pp. 2647.

[18] Mooney. J.M., Adamczad, S., and Clemence, S.P., (1985), "Uplift Capacity of Helix Anchors in Clay and Silt", Uplift Behavior of Anchor Foundations in Soil. Proceedings of ASCE. New York. N.Y., pp.48-72.

[19] Mors, H., (1959), "The Behavior of Mast Foundations Subjected to Tensile Forces", Bautechnik, Vol. (36), pp. 367-378.

[20] Murray, E.J., and Geddes, J.D., (1987), "Uplift of Anchor Plates in Sand", ASCE, Journal of Geotechnical Engineering, Vol.(113), pp. 202215.

[21] Narasimha Rao, S., Prasad, Y.V., Shetty, M.D., and Joshi, V.V., (1989), "Uplift Capacity of Screw Anchors", Geotechnical Engineering, Vol. (20), pp. 139-159.

[22] Narasimha Rao, S., and Prasad, Y.V., (1991), "Estimation of Uplift Capacity of Helical Anchors in Clays", ASCE, Journal of Geotechnical Engineering Division, Vol. (199), pp. 352-357.

[23] Narasimha Rao, S., Prasad, Y.V., and Veeresh, C., (1993), "Behavior of Embedded Model Screw Anchors in Soft Clays", Geotechnique, Vol. (43), pp. 605-614.

[24] Papadopoulou, K., Saroglou, H., and Papadopoulos, V., (2014), "Finite Element Analysis and Experimental Investigation of Helical Micropiles", Geotechnical and Geological Engineering, Vol.(32), No. 4, pp.949-963.

[25] Perko, H.A., (2009), "Helical Piles: Practical Guide to Installation and Design", John Wiley \& Sons, Inc., New York, U.S.A.

[26] Sutherland, H.B., (1965), "Model Studies for Shaft Raising Through Cohesionless Soils", In Proceedings of the $6^{\text {th }}$ International Conference on Soil Mechanics and Foundation Engineering, Montre'al, Que. Vol. (2), pp. 410-413.

[27] Sutherland, H.B., Finlay, T.W., and Fadl, M.O., (1982), "Uplift Capacity of Embedded Anchors in Sand" In Proceedings of the $3^{\text {rd }}$ International Conference on the Behavior of Offshore Structures, Massachusetts Institute of Technology, Cambridge, Mass., pp. 451-463.

[28] Weizhi, S., and Fragaszy, R.J., (1988), "Uplift Testing of Model Anchors", ASCE, Journal of Geotechnical Engineering, Vol. (114), pp. 961983.

[29] Zhang, D.J., (1999), "Predicting Capacity of Helical Screw Piles in Alberta Soils", M.Sc. Thesis, Department of Civil and Environmental Engineering, University of Alberta, Canada. 